\title{
Perfil de Competencia Tecnológica: una propuesta para el sector de Energías Renovables
}

\author{
Norma Candolfi Arballo* \\ Alfredo Hualde Alfaro** \\ Rafael Morales Gamboa** \\ Yessica Espinosa Díaz ${ }^{\star \star \star \star}$
}

Fecha de recibido: 2 de mayo de 2019

Fecha de aprobado: 1 de noviembre de 2019

Para citar este artículo: Candolfi Arballo, N., Hualde Alfaro, A., Morales Gamboa, R., \& Espinosa Díaz, Y. (2020). Perfil de Competencia Tecnológica: una propuesta para el sector de Energías Renovables. Universidad \& Empresa, 22(39), 1-34. https://doi. org/10.12804/10.12804/revistas.urosario.edu.co/empresa/a.7880

\section{Resumen}

La presente investigación tiene por objetivo caracterizar el Perfil de Competencia Tecnológica que representa los niveles de conocimiento tecnológico deseable de los líderes de una organización. La metodología para la construcción del Perfil de Competencia Tecnológica se estructura en tres etapas: el análisis conceptual

* Doctora en Sistemas y Ambiente Educativos en la Universidad de Guadalajara, México. Profesora Investigadora en Facultad de Ciencias de la Ingeniería y Tecnología de la Universidad Autónoma de Baja California. Líder del Cuerpo Académico de Investigación de Educación Continua a Distancia. Miembro de la Red de Calidad de la Educación Mediada por las TICC, la Red de Educación Apoyada en Tecnologías de la Información, Comunicación y Colaboración y la Red Mexicana de Investigadores en Tecnologías Emergentes en la Educación. Correo electrónico: ncandolfi@uabc.edu.mx

** Doctor en estudios latinoamericanos por la Universidad Nacional Autónoma de México (UNAM). Miembro del Sistema Nacional de Investigadores, nivel III. Es investigador del Colegio de la Frontera Norte, adscrito al Departamento de Estudios Sociales, en Baja California, México. Correo electrónico: ahualde@colef.mx

*** Doctor en filosofía con especialidad en inteligencia artificial por la Universidad de Edimburgo, Escocia, maestría en ciencias computacionales por el Instituto Tecnológico y de Estudios Superiores de Monterrey, licenciatura en matemáticas por la UNAM. Correo electrónico: rmorales@suv.udg.mx

**** Doctora en ciencias e ingeniería, por la UABC, México, maestría en administración de tecnologías de información y licenciatura en ciencias de la comunicación y arte digital por el Instituto Tecnológico y de Estudios Superiores de Monterrey, México. Correo electrónico: yespinosa@uabc.edu.mx 
del término de competencia tecnológica, la revisión teórica sobre la valoración de competencias tecnológicas y un estudio de contexto, que responde a una evaluación cualitativa a expertos en el sector evaluado. El caso de estudio analizado se enfoca en la industria de energías renovables, seleccionada por el impacto a nivel mundial y por ser considerado uno de los principales gremios en desarrollo en la frontera norte del estado de Baja California en México. Los resultados se exponen en cuatro ejes que integran las competencias tecnológicas, las cuáles se describen en conocimientos, habilidades y actitudes que un líder de la industria deberá demostrar y que le permitirán el escalamiento industrial de la organización, el crecimiento del capital humano, la mejora de los productos o servicios a partir de la incorporación de las tecnologías de la información, comunicación y colaboración en sus procesos, así como la vinculación y la participación activa en la sociedad y el sector productivo.

Palabras clave: competencias tecnológicas; TICc en la industria; e-competencia; habilidades tecnológicas; energías renovables.

\section{Technological Competence Profile: A Proposal for the Renewable Energy Sector}

\section{Abstract}

The objective of this research is to characterize the Technological Competence Profile, which represents the desirable levels of technological knowledge of the leaders of an organization. The methodology for the construction of the Technological Competence Profile is structured in three stages: the conceptual analysis of the term of technological competence, the theoretical review on the evaluation of technological competences, and a context study, which responds to a qualitative evaluation to experts in the sector evaluated. The case study analyzed focuses on the renewable energy industry for its impact worldwide and for being considered one of the main developing unions in the border area of the state of Baja California in Mexico. The results are set out in four axes, which indicate the competences, skills, and actions that an industry leader must fulfill to demonstrate an adequate level with respect to its technological competencies, which will allow him/her to guide the industrial scale of the organization, the growth of human capital, the improvement of products or services that are offered, from the incorporation of information, communication and collaboration technologies in their processes, as well as a linking and having an active participation in society and the industry.

Keywords: Technological skills; ITC in the industry; e-Competence; technological changes; technological skills.

\section{Perfil de Competência Tecnológica: uma proposta para o setor de Energia Renovável}

\section{Resumo}

A presente pesquisa tem por objetivo caracterizar o Perfil de Competência Tecnológica, que representa os níveis de conhecimento tecnológico desejável dos líderes de uma organização. A metodologia para a construção do Perfil de Competência Tecnológica estrutura-se em três etapas: a análise conceitual do termo de competência tecnológica, a revisão teórica sobre a valoração de competências tecnológicas e um estudo de contexto, que responde a uma avaliação qualitativa de expertos no setor avaliado. O caso de estudo analisado enfoca-se na indústria de energia renovável pelo impacto a nível mundial e por ser considerado um dos principais grémios em desenvolvimento na zona fronteiriça do Estado da Baixa Califórnia. Os resultados se expõem em quatro eixos, os quais indicam as competências, habilidades e ações que um líder da indústria deverá cumprir para demostrar um nível adequado respeito às suas competências tecnológicas, que permitam orientar o escalamento industrial da organização, o crescimento do capital humano, a melhora de produtos ou serviços que se oferecem a partir da incorporação das tecnologias da informação, comunicação e colaboração em seus processos, assim como uma vinculação e participação ativa na sociedade e a indústria.

Palavras-chave: competências tecnológicas; TICC na indústria; e-competence; habilidades tecnológicas; energia renovável. 


\section{Introducción}

El sector productivo agiliza constantemente sus procesos y servicios debido, en gran medida, al desarrollo de las Tecnologías de la Información, Comunicación y Colaboración (TICC) y la naturaleza de las sociedades del conocimiento. Es complicado determinar quién genera el impulso y quién constituye el efecto, es decir, si la sociedad y su evolución propician el avance tecnológico, o bien si las Ticc y sus mecanismos aceleran los cambios sociales. Lo claro es que tanto el sector productivo, como las sociedades del conocimiento motivan a novedosos procesos en los sectores educativos, industriales y gubernamentales para el desarrollo en un país, procesos que se originan desde el área administrativa, productiva, social, cultural, educativa y económica.

Estudios en temáticas de desarrollo tecnológico en la industria (Аміті, 2011; Ahumada et al., 2012; Brito, Garambullo \& Ferreiro, 2014; Buenrostro, 2013; Carrillo \& Hualde, 2000; Carrillo \& Gomis, 2003; Fuentes, 2008; Hualde \& Díaz, 2010; Hualde, Carrillo \& Domínguez, 2008; Iмco, 2006; Marzo, Pedreja \& Rivera, 2006; Núñez-Torrón, 2016) apuntan a los desafíos a los que se enfrentan países subdesarrollados para el logro de altos niveles de competitividad, escalamiento industrial y alcances similares a los registrados por países desarrollados. En un intento por generar estrategias funcionales se pretendía que la adaptación de modelos para la innovación que han resultado exitosos en otras regiones abonaría al crecimiento de la industria de cualquier país (Hualde \& Díaz, 2010; iмco, 2006; Buenrostro, 2013). Se ha generado un cambio en la visión respecto a las propuestas de apropiación tecnológica en los procesos productivos, priorizando al contexto (Sampedro, 2003; Pérez-Jácome \& Aspe, 2012), es decir, investigaciones en donde se delimita la zona de impacto (Vázquez, Estrada \& Reyes, 2014; PND, 2013), elemento que hoy en día es crucial en la estructuración de proyectos, por lo tanto, el replicar o adaptar modelos de una zona a otra no representa una respuesta apropiada que posibilite el desarrollo de la industria, dada la diferencia de condiciones.

Las actividades de los sectores varían a partir de sus objetivos; sin embargo, comparten el interés por el progreso constante del capital humano. Desde hace más de una década, Porter $(2005 ; 2009)$ profundiza en sus estudios sobre las necesidades del capital humano, identificándolo como el elemento más importante para el crecimiento de la industria 
en términos de competitividad y lo que determinará el éxito o fracaso de las empresas. García, Martín y Casado (2009) afirman que el capital humano es el motor que impulsa el desarrollo económico y financiero de la industria, por lo que resulta de suma importancia analizar su comportamiento al interior de una empresa cuando se hace referencia a los cambios tecnológicos, debido a que en la medida que las empresas de un país desarrollen y se apropien de la tecnología, el nivel de competitividad, escalamiento industrial y la productividad apuntarán a porcentajes más favorables.

En México históricamente no se obtienen porcentajes positivos respecto a la apropiación tecnológica de las empresas (IFT, 2018), aun cuando numerosos estudios describen la importancia de la incorporación de tecnología en la industria (Carrillo \& Gomis, 2003; Carrillo \& Hualde, 2000; García, Martín \& Casado, 2009; Hualde \& Díaz, 2010; IMco, 2006; Pérez-Jácome \& Aspe, 2012; Sampedro, 2003; Vázquez, Estrada \& Reyes, 2014; NúñezTorrón, 2016; Secretaría de Economía, 2014; Muñoz, 2016; oCDE, 2017). Las empresas no cuentan en su mayoría con competencias tecnológicas que abonen ideologías innovadoras y les permitan consolidarse a corto o mediano plazo como un gremio de primer nivel, lo que limita su crecimiento a nivel nacional e internacional.

La adopción de TICC en las empresas mexicanas es heterogénea y está constituida de múltiples factores, uno de los más relevantes es la falta de acceso a la formación por parte de los empleados (імсо, 2006; іғт, 2018). En ese sentido, concentrarse en el estudio del talento humano de una organización es prioritario. Conociendo las ventajas que las TICC propician para el desarrollo de las empresas (IFT, 2018; OCDE, 2017; Accenture, 2015) es posible identificar el capital humano como motor habilitador de estrategias encaminadas a la innovación; sin embargo, aún se estudia cómo posibilitar la apropiación y el aprovechamiento de las тісс en las empresas mexicanas. En diversos estudios (Iмсо, 2006; 2016; Buenrostro, 2013; IFT, 2018) se indica que la respuesta radica en trabajar con empresarios, ejecutivos o dirigentes de la industria, de esta manera la adopción de Ticc se extiende en cascada, promoviendo el liderazgo y la gestión al interior de las empresas, estableciendo las condiciones para el aprovechamiento de la tecnología.

En la actualidad, el hecho de dirigir esfuerzos e inversiones para que las empresas adquieran tecnología de punta como una solución para el desarrollo resulta una estrategia obsoleta; tanto políticas y como recursos económicos se destinan a la adquisición de 
equipamiento sin obtener resultados favorables. Un estudio realizado por Select ${ }^{\circledR}$ pone de manifiesto que el $45 \%$ de los ejecutivos mexicanos tienen una percepción poco positiva sobre las ventajas que ofrece la incorporación de TICC como fuente de mejora en la productividad y eficiencia de las empresas (Select, 2005; Lansati, 2005; Аміті, 2011). Aun cuando los reportes sobre adopción tecnológica describen que las empresas con mayor capacidad para utilizar las Ticc en sus procesos de negocio logran aumentar sus ventas casi al doble, en comparación con compañías con una menor capacidad para utilizar las TicC (Moraleda, 2004; IMCO, 2006; 2016; OCDE, 2017; IFT, 2018), la labor se orienta a determinar cuáles son los primeros pasos que hay que dar con los líderes de las empresas: ¿cómo establecer estrategias de desarrollo? ¿Cómo promover programas de adopción de Ticc en las empresas? ¿Cómo obtener financiación para la adquisición de equipo tecnológico?

A partir de los resultados de Select ${ }^{\circledR}$ (2005) numerosas propuestas han surgido: la necesidad de capacitar a los líderes empresariales, el apoyo para equipamiento, el acceso a financiamiento y el fortalecimiento de incubadoras de empresas y centros de desarrollo empresarial, entre otras. Sin embargo, no se analiza el nivel de competencias tecnológicas que poseen los empresarios mexicanos, indagando a profundidad sobre la percepción que se tiene respecto al uso de тісс, la forma en que incorporan tecnología dentro de su empresa, las necesidades tecnológicas de cada sector y una determinada región. Para establecer e impulsar una propuesta de inclusión de las Ticc dentro de un gremio del sector productivo es necesario determinar las características que idealmente un líder/empresario debe tener, para obtener indicadores sobre las competencias y la visión de las Ticc, es decir, describir la estructura del empresario o líder y su relación con las TICC, considerando el contexto como elemento crucial. En la literatura no existe una metodología estructurada que describa los pasos para construir dicho perfil del líder de una empresa en términos tecnológicos, no se identifican las competencias tecnológicas claves que un líder industrial debería tener para favorecer a su empresa con la inclusión de tecnología.

\section{Delimitación geográfica del objeto de estudio}

En México han surgido diversos sectores industriales que son promesa de desarrollo tecnológico y competitividad mundial como el Aeroespacial, la Aeronáutica, la Biotecnología y las Energías Renovables (ER), por mencionar algunos. Estudiar dichos sectores posibilita la formulación de una visión innovadora, en donde sus líderes integren en su plan estratégico 
un enfoque tecnológico y favorezcan el crecimiento de su empresa por medio de las Ticc. Estudios sociales en la industria mexicana se desarrollan en las zonas fronterizas del país (Matus, Carrillo \& Gomis, 2018; Hernández \& Carrillo, 2018; Carrillo \& Micheli, 2017; Brito \& Carrillo, 2017; Gomis \& Carrillo, 2016; Contreras, Plascencia \& Carrillo, 2016; Lévesque et al., 2015; Carrillo, Hualde \& Flacso-México, 2013; Hualde, 2001; Carrión \& Hualde, 2013), en donde la concentración de la industria maquiladora es conveniente y se destaca por la inversión en tecnología de punta, manejo y control de calidad con altos estándares, incorporación de modelos de certificación y acentuada organización empresarial. En Carrillo y Hualde (2000) se describe una investigación sobre la industria maquiladora en la frontera, que reconoce a Ciudad Juárez y Tijuana como las ciudades fronterizas de mayor desarrollo industrial. Resulta determinante que la industria cuya competencia directa es una de las potencias mundiales, como E.E.U.U., y la cercanía territorial propicie una apuesta constante por la innovación. Por ello, las problemáticas de desarrollo en la frontera se definen por las condiciones territoriales que no pueden ser comparadas con las empresas establecidas en el resto del país.

El presente estudio se enfoca en la industria del estado de Baja California, particularmente en el sector de ER, por representar uno de los sectores más importantes e innovadores de la región. En las políticas de desarrollo de Baja California se describe como principal interés el posicionamiento de la industria de ER como agente de cambio, inversión y adquisición económica; actualmente allí se desarrollan proyectos para la generación y exportación de energía derivada de fuentes renovables. Se describe la metodología para la construcción de un perfil de competencia tecnológica dirigido a líderes del sector productivo, con la intención de diseñar un marco de referencia y las características convenientes para quienes se encuentran al frente de las empresas y requieren de conocimientos, habilidades y actitudes con una visión hacia la innovación que sea transferible al resto del capital humano de una organización.

El artículo se estructura de la siguiente manera: la sección 1 describe una revisión teórica de las consideraciones de las competencias tecnológicas y su aplicación en el sector productivo; en la sección 2, se describe la metodología del estudio cualitativo que se realizó para la descripción de las competencias tecnológicas; en la sección 3, se describen dichas competencias tecnológicas divididas en cuatro dimensiones y constituidas por los conocimientos, las habilidades y las actitudes. La sección 4 reflexiona sobre la importancia de la aplicación 
y socialización del perfil de competencia tecnológica para el diagnóstico de necesidades de capacitación de los líderes del sector productivo.

\section{Revisión de la literatura}

\subsection{Primera etapa. Delimitación conceptual de las competencias tecnológicas}

En la primera etapa de la revisión de la literatura, se fundamenta un razonamiento teóricoconceptual en el cuál se discuten consideraciones sobre la visualización del concepto de competencias tecnológicas en la industria, los elementos y las características respecto a un líder del sector industrial, y las dimensiones e indicadores convenientes para la evaluación de competencias tecnológicas en el sector productivo.

Respecto al término de competencia tecnológica se ha encontrado una ilación con los conceptos de capacidad tecnológica, habilidad tecnológica y aprendizaje tecnológico manejados en la literatura por diversos autores y diversas áreas del conocimiento, con definiciones indeterminadas. Los términos antes mencionados tienen relación y en algunos casos dependencia. En Candolfi y Chan (2017) se describe una construcción conceptual de las competencias tecnológicas a partir de un análisis cronológico de su significado y su aplicación, que va desde lo educativo a lo empresarial, analizando cada uno de los términos desde su origen seminal, la transformación de su significado a través del tiempo, el campo de conocimiento en donde fue acuñado, la conceptualización y correlación entre los términos y la reconceptualización aplicada a la industria, en dónde se determina que el término de competencia tecnológica se sitúa en una intersección directa con los significados de capacidad tecnológica, habilidad tecnológica y acumulación de capacidades a partir del aprendizaje tecnológico.

Existen características claves que conectan a cada uno de los términos. El concepto de competencia tecnológica describe el concepto más amplio debido a que implica que se realiza determinada actividad mientras se identifica la "aplicación, relevancia y optimización" de la acción. En el caso de la capacidad, se afirma el potencial para realizar 
una actividad; sin embargo, no se tiene evidencia precisa de qué se hace necesariamente, es la "posibilidad" de acción. En la habilidad, a diferencia de en la capacidad, sí se evidencia la "realización" de la acción en base a una tarea técnica sin mayor profundidad de conocimiento, sin percepción de lo ocurrido y sin una visión clara de los cambios o los beneficios que se generan a futuro. Por tanto, describir competencias tecnológicas constituye una integración de conocimientos, habilidades y actitudes técnicas y especializadas. Se entiende el conocimiento como el resultado del proceso de aprendizaje, que cognitivamente va desde la percepción, asimilación, aplicación y reformulación hasta el perfeccionamiento (Candolfi, Chan \& Rodríguez, 2019). A partir del análisis del término de competencia tecnológica y la diferenciación entre capacidad y habilidad tecnológica es posible identificar los indicadores relevantes para diferenciar las condiciones tecnológicas desde su definición seminal. La definición de competencia tecnológica aplicada a la industria representa la base teórica de la construcción del Perfil de Competencia Tecnológica para los líderes empresariales:

Conjunto de disposiciones cognitivas que desarrolla el capital humano de una organización, con la intención de relacionarse y alcanzar un dominio en el uso consciente o inconsciente de las TICC, referido a la apropiación e incubación tecnológica de servicios, procesos o productos que generen beneficios y crecimiento a la empresa, fundamentado estrictamente en el trabajo colaborativo de su personal (Candolfi, Chan \& Rodríguez, 2019).

El término de competencia tecnológica se considera un sistema finito, lo cual indica que puede ser medido por considerar un límite en determinado espacio o tiempo de revisión; este se describe como un "conjunto de disposiciones cognitivas", que son definidas en el proyecto de modelos del pensamiento de la Universidad de Harvard como "el proceso que expresan los individuos a través de un comportamiento y a la utilización frecuente y consistente de habilidades cognitivas" (Tishman \& Andrade, 1998). A su vez, se describen tres elementos principales que se relacionan con las habilidades cognitivas: la sensibilidad, la motivación y la habilidad, que forman la base conceptual de la definición de competencias tecnológicas.

Se considera la construcción conceptual con la intención de estructurar una definición de las competencias tecnológicas centrada en el capital humano de una organización, a 
partir de una postura de estudio en los sectores productivos para visualizar el dominio tecnológico desde una perspectiva de estado consciente e inconsciente de la tecnología, un estado en el que se deja de pensar en la incorporación de Ticc como un elemento instrumental, modificando una estructura cognitiva transparente, cotidiana y espontánea con la tecnología. Así mismo, resulta relevante suponer el trabajo colaborativo del personal como una característica central, debido a que el aprendizaje y el desarrollo de habilidades es generado a partir de la experiencia organizacional, la del individuo y la de sus pares según el contexto.

\subsection{Segunda etapa. Análisis de investigaciones previas}

En la segunda etapa de la revisión de la literatura se analizaron publicaciones científicas y literatura complementaria - literatura gris - con la intención de ampliar el marco teórico respecto a la valoración y evaluación de competencias tecnológicas desde un plano de aplicación y determinar las consideraciones en cuanto al desempeño dentro del sector de ER. En las tablas 1 y 2 se presentan los conjuntos de referencias analizadas.

Tabla 1. Análisis de la aplicación de competencias tecnológicas

\begin{tabular}{|c|c|c|}
\hline \multicolumn{3}{|c|}{ Competencias tecnológicas desde la perspectiva de la industria } \\
\hline & Referencias consultadas & Hallazgos relevantes \\
\hline $\begin{array}{l}\text { Análisis en } \\
\text { el marco } \\
\text { internacional }\end{array}$ & $\begin{array}{l}\text { (eCompetence, 2016; Patel \& } \\
\text { Pavitt, 1997; Renaud, 1990; Urraca, } \\
\text { 2013; Chomsky, 1965; Hymes, } \\
\text { 1974; González, 1999; Cabello, } \\
\text { 2004; Motta et al., 2013; Romijn \& } \\
\text { Albadalejo, 2002; ITIL, 2017) }\end{array}$ & $\begin{array}{l}\text { El marco europeo de las e-competencias define cuarenta } \\
\text { competencias en TIC que deberán ser promovidas y } \\
\text { desarrolladas dentro de la industria para incrementar } \\
\text { su desempeño. Así mismo, la Information Technology } \\
\text { Infrastructure Library (ITIL) propone una serie de estándares } \\
\text { y procedimientos guías para asegurar el desarrollo de in- } \\
\text { fraestructura, apropiación y operaciones claras basadas en } \\
\text { TI al interior de las organizaciones. En otras investigaciones } \\
\text { se aborda la evaluación de competencias tecnológicas des- } \\
\text { de diversas perspectivas: evaluación cuantitativa, cualitativa } \\
\text { o mixta. Las dimensiones propuestas se dirigen desde la } \\
\text { percepción, actividad social, interactividad, uso de conteni- } \\
\text { dos y actualización de prácticas. }\end{array}$ \\
\hline
\end{tabular}




\section{Competencias tecnológicas desde la perspectiva de la industria}

\section{Referencias consultadas}

Análisis en el (Reynaga \& Ruiz, 2003; Marzo,

marco nacional Pedreja \& Rivera, 2006; García \&

(México)
Romero, 2011; Sampedro, 2003)

\section{Hallazgos relevantes}

Estudios sobre competencias exigidas en el sector productivo, con énfasis en las habilidades tecnológicas, en algunos casos se abordan desde un panorama regional, la experiencia en áreas específicas o bien desde alguna organización en particular. En general, son casos de estudio de las competencias y el trabajo; algunos autores resaltan dimensiones y categorías de estudios sobre las competencias profesionales y el papel de las TICC.

Análisis en el (Hualde \& Díaz, 2010; Hualde, marco regional Carrillo \& Domínguez, 2008; (Baja California) Fuentes, 2008; Ahumada et al., 2012)

En el Colegio de la Frontera Norte se han realizado estudios en el sector productivo, analizando a la industria en el Estado. Los estudios tienen un enfoque de análisis económico y social, en donde se identifican habilidades y capacidades laborales del capital humano que compone las organizaciones en Baja California y lo compara con otros Estados fronterizos y manufactureros.

Diversidad en la (Villanueva \& Casas, 2010; Romijn evaluación de competencias tecnológicas \& Albadalejo, 2002; Motta et al., 2013; Patel \& Pavitt, 1997; Urraca, 2013; Gil, 2003; Ordóñez et al., 2015; Cabello, 2004; González, 1999) Investigaciones aplicadas en las que se realizan propuestas de evaluación de competencias tecnológicas desde diversos puntos de vista. En las propuestas metodológicas se realizan aportaciones sobre indicadores, métricas y dimensiones de evaluación dirigidas a una población en particular; en algunos casos se presentan instrumentos de evaluación.

Tabla 2. Análisis del sector de ER

\begin{tabular}{|c|c|c|}
\hline \multicolumn{3}{|c|}{ Caracterización del sector de ER } \\
\hline & Referencias consultadas & Hallazgos \\
\hline $\begin{array}{l}\text { Globalización } \\
\text { del sector }\end{array}$ & (SENER, 2011; UNEP, 2015) & $\begin{array}{l}\text { Condiciones globales en materia de ER y la participación de } \\
\text { México en los compromisos en un marco de acción global. }\end{array}$ \\
\hline $\begin{array}{l}\text { Perspectiva } \\
\text { nacional } \\
\text { (México) }\end{array}$ & $\begin{array}{l}\text { (Secretaría de Economía, 2014; } \\
\text { Gasca, 2015; PND, 2013; SENER, } \\
\text { 2013; 2016a; 2016b; GOB-PEAER, } \\
\text { 2013; CRE, 1993; PRODESEN, 2017; CO- } \\
\text { NUEE, 2008; AMEXCID, 2012; GIZ, 2012; } \\
\text { 2017; CGCEREE, 2016; INEEL, 2001; } \\
\text { CFE, 2008; 2012a; 2012b; 2017) }\end{array}$ & $\begin{array}{l}\text { Estudio del sector de ER en México, así como su desarrollo y } \\
\text { oportunidades de mejora. La revisión documental se enfoca en } \\
\text { reportes, planes y programas de organismos gubernamentales, } \\
\text { en los que se analiza la reforma energética, el modelo de } \\
\text { funcionamiento de dicha reforma, la incorporación del modelo } \\
\text { energético nacional, la ER y su papel en la reforma energética y } \\
\text { el soporte gubernamental. }\end{array}$ \\
\hline $\begin{array}{l}\text { Investigación y } \\
\text { desarrollo }\end{array}$ & (CEMIE, 2015) & $\begin{array}{l}\text { Los centros mexicanos de innovación en energía son una } \\
\text { respuesta a las necesidades de integración e impulso de la ER } \\
\text { en el país, que representan la vinculación y cooperación entre } \\
\text { instituciones de educación superior, centros de investigación, } \\
\text { sector productivo y organismos gubernamentales, con la inten- } \\
\text { ción de generar proyectos sobre desarrollo tecnológico que } \\
\text { permitan el aprovechamiento de las potencialidades respecto a } \\
\text { ER en México. }\end{array}$ \\
\hline
\end{tabular}




\begin{tabular}{|c|c|c|}
\hline \multicolumn{3}{|c|}{ Caracterización del sector de ER } \\
\hline & Referencias consultadas & Hallazgos \\
\hline $\begin{array}{l}\text { Historia y } \\
\text { evolución en el } \\
\text { estado de Baja } \\
\text { California }\end{array}$ & $\begin{array}{l}\text { (GOB-BC, 2015; Subsecretaría } \\
\text { SENER, 2015) }\end{array}$ & $\begin{array}{l}\text { Análisis cronológico de la evolución de ER en el estado de Baja } \\
\text { California. }\end{array}$ \\
\hline $\begin{array}{l}\text { Industria fron- } \\
\text { teriza }\end{array}$ & $\begin{array}{l}\text { (GOB-BC, 2015; COCEF, 1993; } \\
\text { COCEF/BECC, 2013; GOB-BC, 2015; } \\
\text { Fuentes, 2011) }\end{array}$ & $\begin{array}{l}\text { Análisis en Baja California sobre las consideraciones respecto a } \\
\text { su posición geográfica, si esto representa una ubicación clave } \\
\text { para la integración y desarrollo de empresas, identificación de } \\
\text { los sectores con un mayor crecimiento, actividades que favore- } \\
\text { cen el potencial económico y de conocimiento en México, así } \\
\text { como la revisión de fuentes de recursos naturales que resulten } \\
\text { atractivas para el posicionamiento de la industria. }\end{array}$ \\
\hline Talento humano & (SENER, 2010; SIE, 2015) & $\begin{array}{l}\text { Identificación de fortalezas y debilidades del capital humano, } \\
\text { así como de los programas de capacitación y actualización } \\
\text { profesional. }\end{array}$ \\
\hline
\end{tabular}

\section{Metodología de evaluación}

Construir un Perfil de Competencia Tecnológica en el sector de ER, que represente aquellas características tecnológicas necesarias para que un líder empresarial oriente su empresa hacia la innovación, el crecimiento, el reconocimiento internacional y un punto de identidad y competitividad mundial. Esto representa una propuesta ambiciosa, puesto que la manipulación de artefactos de vanguardia responde literalmente a la capacitación y práctica diaria. En contraposición, la visión, apropiación y distribución de un plan de trabajo basado en expectativas puede resultar arriesgado. En el presente análisis, los esfuerzos se dirigen a la apropiación e impulso desde quienes rigen las políticas de desarrollo de la empresa previo a la capacitación e indagación del capital humano, por ello, el estudio es referido a los líderes empresariales.

La metodología para la construcción del Perfil de Competencia Tecnológica se divide en tres etapas. La primera corresponde al soporte conceptual de la investigación, en dónde se realizó una revisión sistemática de la literatura con la intención de definir la competencia tecnológica aplicada al ambiente productivo o de las organizaciones en la industria (sección 1.1); la segunda etapa presenta un análisis bibliográfico de publicaciones científicas y literatura gris - término que identifica documentos oficiales, gubernamentales y académicos 
como informes o reportes técnicos-sobre las competencias tecnológicas del capital humano a nivel regional, nacional e internacional (sección 1.2). La tercera etapa es un estudio cualitativo de expertos en ER, en dónde el perfil del participante se orientaba a investigadores, docentes y representantes de gobierno en el sector (sección 2.1). En la figura 1 se describe gráficamente la metodología para la construcción del Perfil de Competencia Tecnológica.

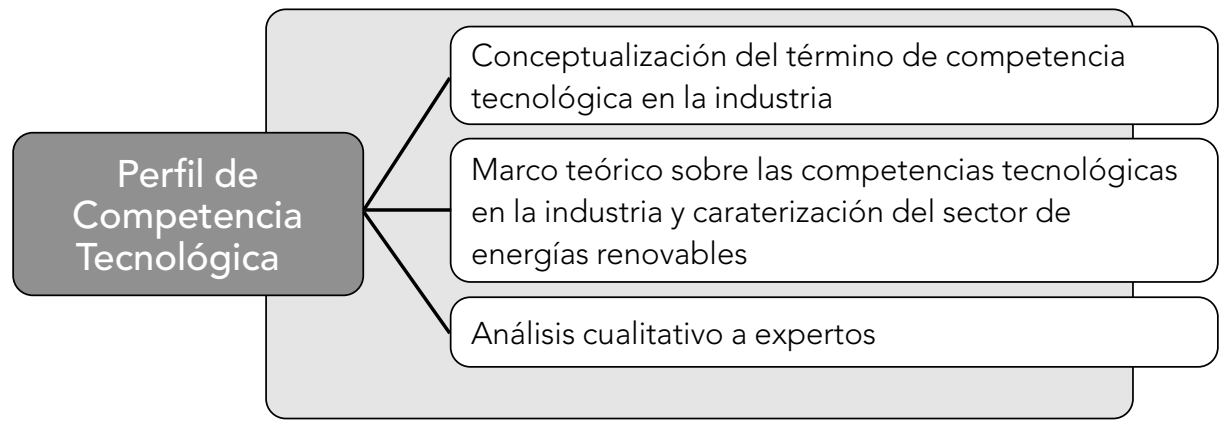

Figura 1. Metodología para la construcción del Perfil de Competencia Tecnológica Fuente: elaboración propia

\subsection{Descripción del estudio cualitativo}

Se realiza un estudio de tipo exploratorio con un enfoque cualitativo en base a la apreciación de expertos, que refleja el contexto de la industria a partir de la visión de investigadores, gestores y representantes gubernamentales que participan en la industria de ER en Baja California. Para la selección de expertos se consideraron participantes con un nivel avanzado en la dirección de proyectos en ER, quienes se distinguen por atender necesidades de la industria regional, una participación en actividades encaminadas a la incorporación tecnológica, dirigentes de programas de licenciatura o posgrado en el área de ER, así como representantes de instituciones gubernamentales, en todos los casos se requería una visión clara sobre las potencialidades de la ER en Baja California.

Los datos para el análisis se obtuvieron de entrevistas semiestructuradas en donde se definieron ejes generales de atención y objetivos particulares para la orientación del discurso, marcando tendencias para la recopilación de datos con los entrevistados. Los objetivos planteados, constituyeron una guía del discurso como propuesta de seguimiento, debido a que la orientación de la entrevista varió dependiendo del ejercicio y el área de conocimiento del experto entrevistado. La técnica seleccionada para la revisión de resultados fue el análisis 
del discurso (Sagoyo, 2007). En la figura 2 se presentan las etapas del análisis, en un primer nivel se define el objeto de estudio, en donde se describe y delimita la investigación, contextualizando la problemática; en un segundo nivel se propone la definición de la teoría, en dónde se determinan las categorías y subcategorías de análisis; en el tercer nivel se presenta la operacionalización, momento en el que se indica el peso/validez de las categorías y subcategorías de análisis, indicando prioridades dentro de toda la unidad de análisis (Vílchez, 2004); en el cuarto nivel, se define la selección del corpus, las instancias discursivas, que se representan con texto y video; en el quinto, se presenta el análisis del discurso, en él se definen las formas y la orientación del análisis, se implementa la interpretación discursiva, observando tanto las instancias discursivas, como las relaciones que se presentan entre ellas, así como el contexto en el que se producen; en el sexto, se presenta la interpretación, se examina la concordancia entre los datos obtenidos de las entrevistas en contraste con la fundamentación teórica, y en el séptimo nivel, la "explicación”, se describen los hallazgos.

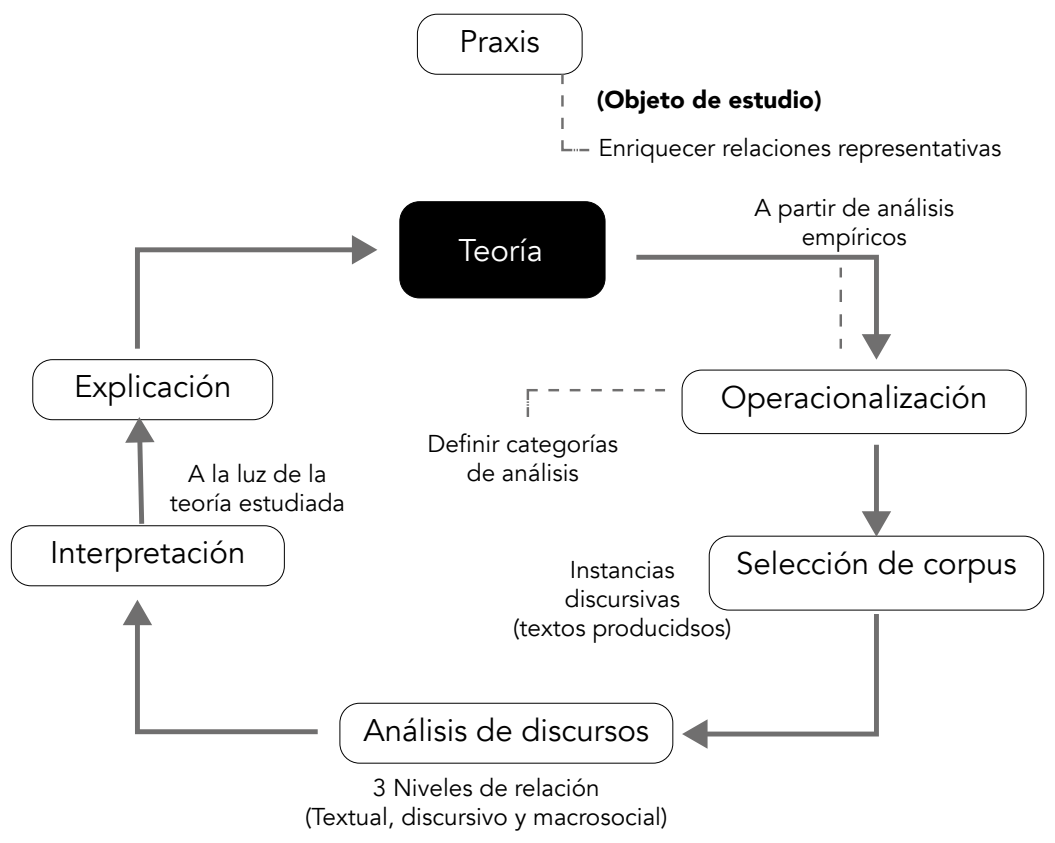

Figura 2. Procedimiento para el análisis del discurso Fuente: elaborada a partir de Sayago (2014).

Se entrevistaron 13 expertos en Baja California, 11 de ellos se encuentran adscritos a instituciones de educación superior o centros de investigación y dos expertos más se desempeñan en el sector gubernamental en la Comisión Estatal de Energía y la Secretaría de Protección al Ambiente. Se realizaron las entrevistas en dos modalidades, presencial 
y virtual. ${ }^{1}$ El análisis e interpretación se establece mediante un modelo de categorización inductiva (Andréu, s.f.), se dividen los textos por categorías y subcategorías, posteriormente, se realiza una descripción y correlación de lo que se dice, clasificando los discursos. Las categorías y subcategorías de análisis permiten ordenar con mayor claridad los textos que se obtienen de las entrevistas, etiquetando o asociando lo que el experto opina sobre una pregunta o tema. En la tabla 3 se describen las categorías y subcategorías, indicando el nombre y un acrónimo, se describen las subcategorías asociadas a cada categoría, se indica el significado de cada una de las subcategorías de análisis y por último se describe el código de análisis para orientar la interpretación del discurso.

Tabla 3. Descripción de categorías, subcategorías y códigos de análisis

\begin{tabular}{|c|c|c|}
\hline \multicolumn{3}{|c|}{ I. Aspectos de la industria de energías renovables (IER) } \\
\hline $\begin{array}{l}\text { Subcategoría } \\
\text { (clasificación del } \\
\text { discurso) }\end{array}$ & Descripción de subcategoría & $\begin{array}{l}\text { Códigos de análisis } \\
\text { (interpretación del } \\
\text { discurso) }\end{array}$ \\
\hline Principales proyectos & $\begin{array}{l}\text { Representatividad de la IER en Baja California a nivel nacional e } \\
\text { internacional, dando importancia a los proyectos transnaciona- } \\
\text { les, por su ubicación como Estado. }\end{array}$ & $\begin{array}{l}\text { Registro de actividad } \\
\text { productiva. }\end{array}$ \\
\hline $\begin{array}{l}\text { Barreras en el } \\
\text { crecimiento de la IER }\end{array}$ & $\begin{array}{l}\text { Condiciones que limitan el crecimiento de la IER en el Estado, } \\
\text { ya sea para el desarrollo de nuevos proyectos o el registro de } \\
\text { empresas y el nivel de consolidación. }\end{array}$ & $\begin{array}{l}\text { Política, tecnológica, } \\
\text { comunicación, técnica. }\end{array}$ \\
\hline $\begin{array}{l}\text { Fortalezas del sector de } \\
\text { ER en Baja California }\end{array}$ & $\begin{array}{l}\text { Indicadores que favorecen al sector de ER desde lo geográfico, } \\
\text { político, cultural y económico, que atraen la inversión local, } \\
\text { nacional e internacional. }\end{array}$ & $\begin{array}{l}\text { Potencial energético, } \\
\text { capital humano y eco- } \\
\text { nómico. }\end{array}$ \\
\hline Impulso de PYME en ER & $\begin{array}{l}\text { Contexto de las PYME en Baja California y sus oportunidades de } \\
\text { crecimiento a mediano y largo plazo, así como las recomenda- } \\
\text { ciones de ocupación para su ampliación y progreso. }\end{array}$ & $\begin{array}{l}\text { Identificación de servi- } \\
\text { cios. }\end{array}$ \\
\hline $\begin{array}{l}\text { Clúster de ER en el Baja } \\
\text { California }\end{array}$ & Conocimiento del registro del clúster de ER. & Barrera de crecimiento. \\
\hline $\begin{array}{l}\text { Relación entre industria- } \\
\text { gobierno-educación }\end{array}$ & $\begin{array}{l}\text { Identificar la sinergia entre los tres sectores para el desarrollo } \\
\text { de proyectos e iniciativas relacionadas a ER. }\end{array}$ & $\begin{array}{l}\text { Potencialidades, obstá- } \\
\text { culos y propuestas. }\end{array}$ \\
\hline
\end{tabular}

1 Las entrevistas presenciales se llevaron acabo en el lugar de trabajo del entrevistado. Las entrevistas en modalidad virtual se realizaron por medio de una videoconferencia utilizando las aplicaciones de Skype o Bluejeans, según la preferencia del entrevistado. 


\begin{tabular}{|c|c|c|}
\hline \multicolumn{3}{|c|}{ II. Aspectos de Profesionales/Líderes en Energías Renovables (PER) } \\
\hline $\begin{array}{l}\text { Subcategoría } \\
\text { (clasificación del } \\
\text { discurso) }\end{array}$ & Descripción de subcategoría & $\begin{array}{l}\text { Códigos de análisis } \\
\text { (interpretación del } \\
\text { discurso) }\end{array}$ \\
\hline $\begin{array}{l}\text { Competencias / } \\
\text { exigencias del líder de } \\
\text { empresa en ER }\end{array}$ & $\begin{array}{l}\text { Recomendaciones respecto a las características del dirigente } \\
\text { de empresas de ER en base a lo que se identifica como priorita- } \\
\text { rio por atender y sus necesidades de habilitación. }\end{array}$ & $\begin{array}{l}\text { Exigencias informacio- } \\
\text { nales, empresariales y } \\
\text { tecnológicas. }\end{array}$ \\
\hline $\begin{array}{l}\text { Oferta en formación } \\
\text { (licenciatura, posgrado, } \\
\text { certificación) }\end{array}$ & $\begin{array}{l}\text { Validación de la oferta educativa en el Bajo California respecto } \\
\text { a la formación profesional, seguimiento en posgrado, así como } \\
\text { cursos de capacitación y certificaciones para el capital humano } \\
\text { de la IER, evaluando los perfiles de egreso y las condiciones para } \\
\text { incorporarse al mercado laboral a mediano plazo. }\end{array}$ & $\begin{array}{l}\text { De las buenas prácticas, } \\
\text { de las oportunidades } \\
\text { de mejora. }\end{array}$ \\
\hline $\begin{array}{l}\text { Oportunidades de parti- } \\
\text { cipación y desarrollo de } \\
\text { especialistas en ER }\end{array}$ & $\begin{array}{l}\text { Apertura para la incursión en proyectos de ER, así como en } \\
\text { planes y programas en conjunto con instituciones gubernamen- } \\
\text { tales y educativas. }\end{array}$ & $\begin{array}{l}\text { Habilidades empresa- } \\
\text { riales, identificación de } \\
\text { necesidades regionales, } \\
\text { dominio técnico de las } \\
\text { energías renovables. }\end{array}$ \\
\hline \multicolumn{3}{|c|}{ III. Aspectos Socioculturales de las Energías Renovables (SCER) } \\
\hline $\begin{array}{l}\text { Subcategoría } \\
\text { (clasificación del } \\
\text { discurso) }\end{array}$ & Descripción de subcategoría & $\begin{array}{l}\text { Códigos de análisis } \\
\text { (interpretación del } \\
\text { discurso) }\end{array}$ \\
\hline $\begin{array}{l}\text { Representatividad de } \\
\text { las ER en Baja California }\end{array}$ & $\begin{array}{l}\text { Percepción de la comunidad sobre la penetración de proyectos } \\
\text { de ER, sus experiencias previas y los significados que tienen } \\
\text { sobre el sector y sus representantes. }\end{array}$ & $\begin{array}{l}\text { Imagen social sobre la } \\
\text { energía renovable. }\end{array}$ \\
\hline $\begin{array}{l}\text { Beneficios e impacto } \\
\text { social de proyectos en } \\
\text { zonas vulnerables }\end{array}$ & $\begin{array}{l}\text { Iniciativas y resultados sobre el desarrollo de proyectos enca- } \\
\text { minados al progreso de zonas menos favorecidas o vulnerables } \\
\text { por la ubicación geográfica, el nivel económico o las condicio- } \\
\text { nes políticas y sociales. }\end{array}$ & $\begin{array}{l}\text { Proyectos de aplica- } \\
\text { ción. }\end{array}$ \\
\hline Globalización de la IER & $\begin{array}{l}\text { Posicionamiento de la industria del sector de ER respecto al } \\
\text { diseño y desarrollo de productos y servicios a nivel mundial. }\end{array}$ & $\begin{array}{l}\text { México en el mundo de } \\
\text { la ER. }\end{array}$ \\
\hline
\end{tabular}

\section{Resultados y discusión}

\subsection{Obtención de resultados}

Una vez clasificado cada texto en categorías, con una numeración consecutiva en cada aportación, se interpretó el discurso, resaltando los códigos de análisis en cada caso. Se categorizaron un total de 84 textos, los cuales se distribuyeron de la siguiente manera: la categoría IER tuvo 46 textos organizados en sus 6 subcategorías; la categoría PER tuvo 31 textos en sus 3 subcategorías, y la categoría sCER, 13 textos en sus 3 subcategorías. A continuación, se presenta un ejemplo sobre el abordaje, la clasificación de textos y la interpretación del discurso elaborado. Se indica en primer lugar la categoría y subcategoría de 
análisis, posteriormente se enumeran las citas textuales de los expertos (en letra cursiva) y al final se describe la interpretación del discurso en donde se distingue el código de análisis (subrayado).

\subsubsection{Categorización}

Categoría IER | subcategoría fortalezas del sector de ER en Baja California

[IER25] Las potencialidades de ER en Baja California son principalmente cuatro: la microbidráulica, eólica, solar, geotérmica.

[IER26] Tener mucho recurso de sol/viento.

[IER27] En el tema de geotermia hay dos grandes aplicaciones, es decir dos fuentes de recursos: uno es para generar electricidad como el de cerro prieto en Mexicali, esa planta es la más grande de Latinoamérica, así como esa hay 5 en México (más chicas), en Michoacán los Azufres, en Puebla los Humeros, Baja California Sur las tres vírgenes casi en frontera entre Baja California Sury Baja California, estas 4 están operadas por la CFE, en Nayarit hay una privada por el grupo Dragón (generando electricidad); estas cinco plantas nos tienen como país en el cuarto o quinto lugar a nivel mundial en cuanto a la capacidad instalada para generar electricidad a partir de geotérmica, no hay muchos porque los recursos geotérmicos solo se encuentran en ciertas características con capacidades geológicas. [IER28] Actualmente hay capital humano calificado. Tenemos 12 patentes y resultados. Formamos recursos bumanos y producimos producto tecnológico (posgrado).

[IER29] El valor para poder implementar y correr cosas de energía solar sobre todo fotovoltaica, se ha abatido al precio de cualquier convencional, digamos del 2010 (aún era caro) pero al 2016 ya estaba igual.

\subsubsection{Interpretación}

Los expertos confirman que los recursos para la generación de energía por medios renovables en Baja California son variados y grandes, con potencialidades energéticas. Resaltan los recursos del sol, el viento y la geotérmica; a diferencia del resto del país, el Baja California se identifica como una isla energética. A nivel posgrado se promueve incursionar en proyectos de ER bajo un esquema de diseñadores de nuevos productos y de aplicación en problemáticas del Estado, esto es un plus al capital humano que se 
actualiza en la industria en Baja California, puesto que en continuidad con la formación profesional, el participante de un posgrado mejora sus habilidades técnicas y adquiere competencias para incursionar en el mercado y vincularse junto con sus productos novedosos a una aplicación real que puede llegar a patentar, registrar o vender; como oportunidad de crecimiento se identifica que hacen falta expertos en el área de geotérmica. Por pertenecer a la zona fronteriza adquiere ventajas económicas respecto a otros Estados, ya que la facilidad de exportación y el acceso a mayores productos o servicios nacionales o extranjeros reducen las cotizaciones constantemente.

\subsection{Descripción general del Perfil de Competencia Tecnológica para el sector de energías renovables. Un retrato hablado}

Definir un Perfil de Competencia Tecnológica obliga al investigador a considerar la multidisciplinariedad y la intersección de diversas áreas de conocimiento involucradas, que implican una visualización del estudio desde una visión de lo ecosistémico en lo educativo (Chan, 2016), o bien un ecosistema de innovación en lo socioeconómico (Carrillo et al., 2016).

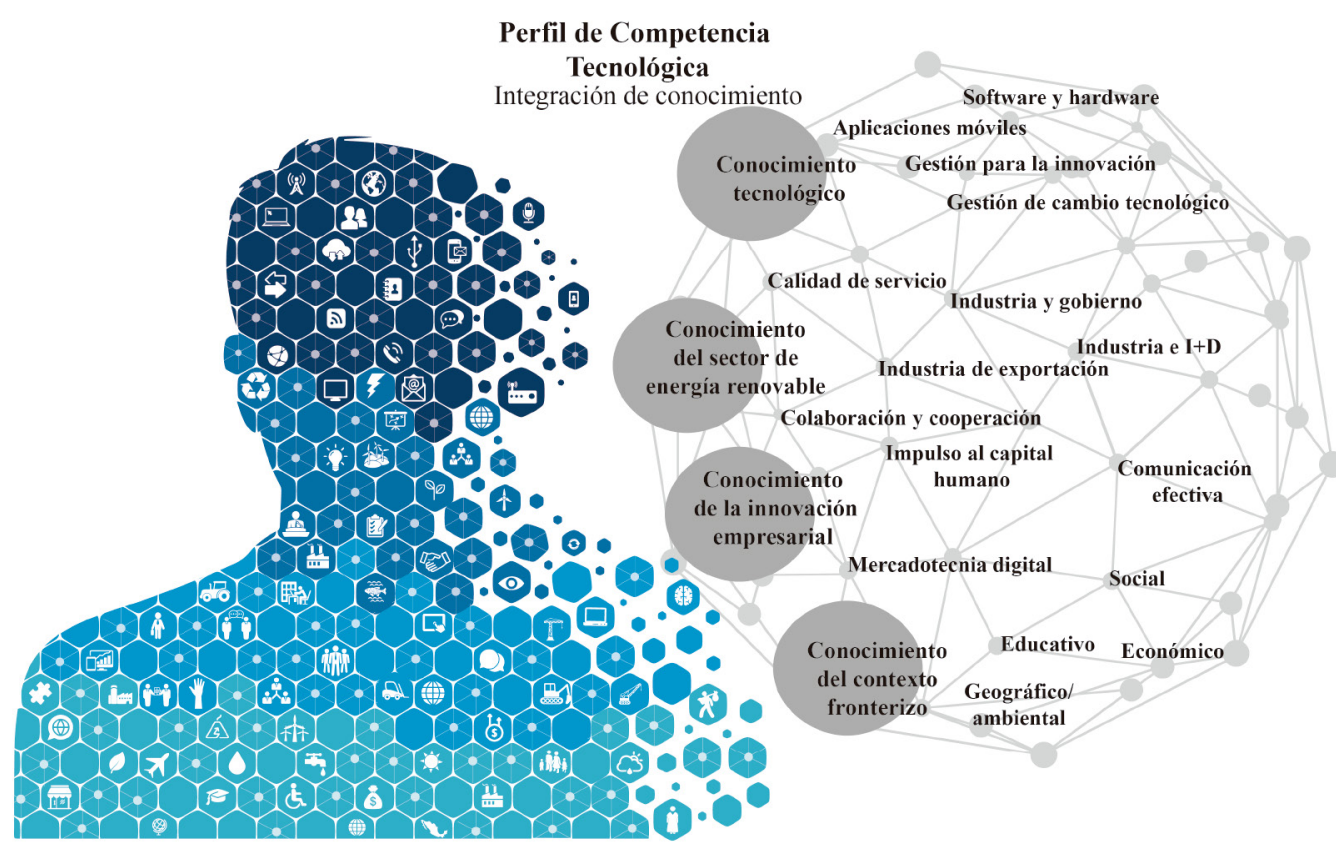

Figura 3. Estructura del Perfil de Competencia Tecnológica en la industria de ER 
La construcción de un Perfil de Competencia Tecnológica se ejemplifica como una silueta constituida por una diversidad de elementos que se unen para la formación de un empresario idóneo tecnológicamente hablando. En la figura 3 se representa a un líder del sector productivo constituido a través de múltiples áreas de conocimiento, interactuando en un entorno globalizado, en donde las exigencias se modifican, se transforman y constantemente evolucionan. Por ello la capacidad de autoformación, adaptación y visión innovadora mantiene activo y en equilibro el progreso de la empresa que representa. Los ejes principales que integran el denominado Perfil de Competencia Tecnológica orientado a líderes de las pequeñas y medianas empresas del sector de ER en el norte de México son los conocimientos tecnológicos, del sector de ER, de innovación empresarial y del contexto fronterizo.

\subsection{Composición del Perfil de Competencia Tecnológica para el sector de energías renovables. Figura a detalle}

Se describen los indicadores puntuales de cada uno de los ejes que componen el Perfil de Competencia Tecnológica, producto de las tres etapas que integran la metodología para su construcción, descrita en las secciones anteriores.

\subsubsection{Consideraciones del Perfil de Competencia Tecnológica sobre el conocimiento tecnológico}

Se enlistan en la tabla 4 el conocimiento, las habilidades y las actitudes que debe reunir el Perfil de Competencia Tecnológica en el sector de ER, respecto al eje de consideraciones tecnológicas. En el primer eje se aborda la descripción general sobre el denominado marco europeo de las e-competencias/European e-Competence Framework y el modelo de referencia sFiA (Skills Framework for the Information Age) (e-Competence, 2016) focalizando la importancia de su aplicación en la apreciación de habilidades tecnológicas en los países europeos y que a nivel mundial ha representado un documento guía para la elaboración de programas para el desarrollo del sector productivo. Múltiples proyectos han surgido como respuesta a la demanda de e-competencias.

En Burillo, Dueñas y Cuadrado (2012) se aborda el proyecto Competencias profesionales eтіс en mercados emergentes, promovido por la Fundación de Tecnologías de la Información 
(FTI) en colaboración con la Asociación de Empresas de Electrónica, Tecnologías de la Información, Telecomunicaciones y Contenidos Digitales de España (AMETIC), en el cuál se plantea la apropiación de competencias tecnológicas y sus niveles de conocimiento a partir de lo recomendado en el marco europeo de las e-competencias y SFIA, describiendo características para la construcción de un Perfil de Competencia Tecnológica, tanto del segmento de e-inclusión como en el de consumo eléctrico eficiente, ambos de interés para la definida estrategia Europa 2020 (Comisión Europea, 2015). Vistos desde la tendencia tecnológica, económica y profesional, los indicadores de competencias y habilidades recomendadas registran una base de conocimiento para quienes son líderes de las empresas en ese sector o mercado. Respecto al ámbito tecnológico, se consideran las aplicaciones, productos, sistemas, servicios, estandarización, seguridad, innovación y proyección futura; en el ámbito económico, la posición en el sector TICC por sus actividades, mercado, cadena de valor y modelos de negocios; y en el ámbito profesional, son importantes los niveles de formación, las capacidades, conocimientos, competencias y los perfiles profesionales, la consciencia del usuario y el soporte en la toma de decisiones.

Tabla 4. Consideraciones del conocimiento tecnológico del Perfil de Competencia Tecnológica Bases teóricas: marco europeo de las e-competencias/European e-Competence Framework (e-CF), el modelo de referencia SFIA, mercados emergentes, ITIL.

\begin{tabular}{|c|c|c|}
\hline Conocimiento & Habilidad & Actitud \\
\hline $\begin{array}{l}\text { Software y } \\
\text { hardware }\end{array}$ & 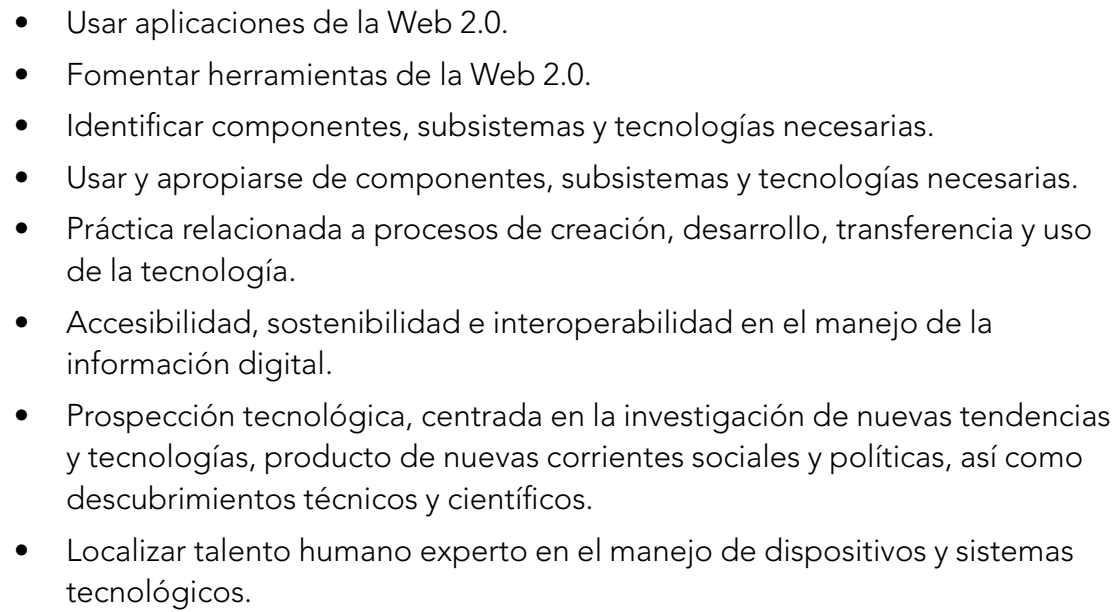 & $\begin{array}{l}\text { Comunicativa } \\
\text { De iniciativa } \\
\text { Integradora } \\
\text { Liderazgo } \\
\text { Proactiva } \\
\text { Promotor } \\
\text { Reflexiva }\end{array}$ \\
\hline
\end{tabular}




\begin{tabular}{|c|c|c|}
\hline Conocimiento & Habilidad & Actitud \\
\hline $\begin{array}{l}\text { Aplicaciones } \\
\text { móviles }\end{array}$ & $\begin{array}{l}\text { - Usar y dominar equipo móvil (Smartphone/tabletas electrónicas). } \\
\text { - Usar aplicaciones móviles de comunicación, de colaboración y cooperación, } \\
\text { - Usar herramientas para la vigilancia tecnológica asociada a la innovación } \\
\text { tecnológica y a un trabajo sistemático de planificación, adquisición, } \\
\text { producción y difusión de la información. } \\
\text { - Planificar los recursos móviles tecnológicos, propiciando una ventaja } \\
\text { competitiva. }\end{array}$ & $\begin{array}{l}\text { Participativa } \\
\text { Empatía } \\
\text { Proactiva } \\
\text { Comunicativa }\end{array}$ \\
\hline $\begin{array}{l}\text { Gestión para la } \\
\text { innovación }\end{array}$ & $\begin{array}{l}\text { - Seleccionar personal adecuado para el manejo de componentes, } \\
\text { subsistemas y tecnologías necesarias. } \\
\text { - } \text { - Mominar y adaptar la reingeniería de procesos y la ingeniería concurrente. } \\
\text { nuevos productos o servicios, la puesta en marcha en el mercado y el control } \\
\text { de la ventana de tiempo que se acorta progresivamente. } \\
\text { - } \quad \text { Integrar un equipo multidisciplinario de empleados al interior de la empresa. } \\
\text { - } \text { seguridar por medio de herramientas tecnológicas, considerando temáticas de } \\
\text { segare, hardware, infraestructura e información. }\end{array}$ & $\begin{array}{l}\text { Compromiso } \\
\text { Confianza } \\
\text { Cordial }\end{array}$ \\
\hline $\begin{array}{l}\text { Gestión } \\
\text { de cambio } \\
\text { tecnológico }\end{array}$ & 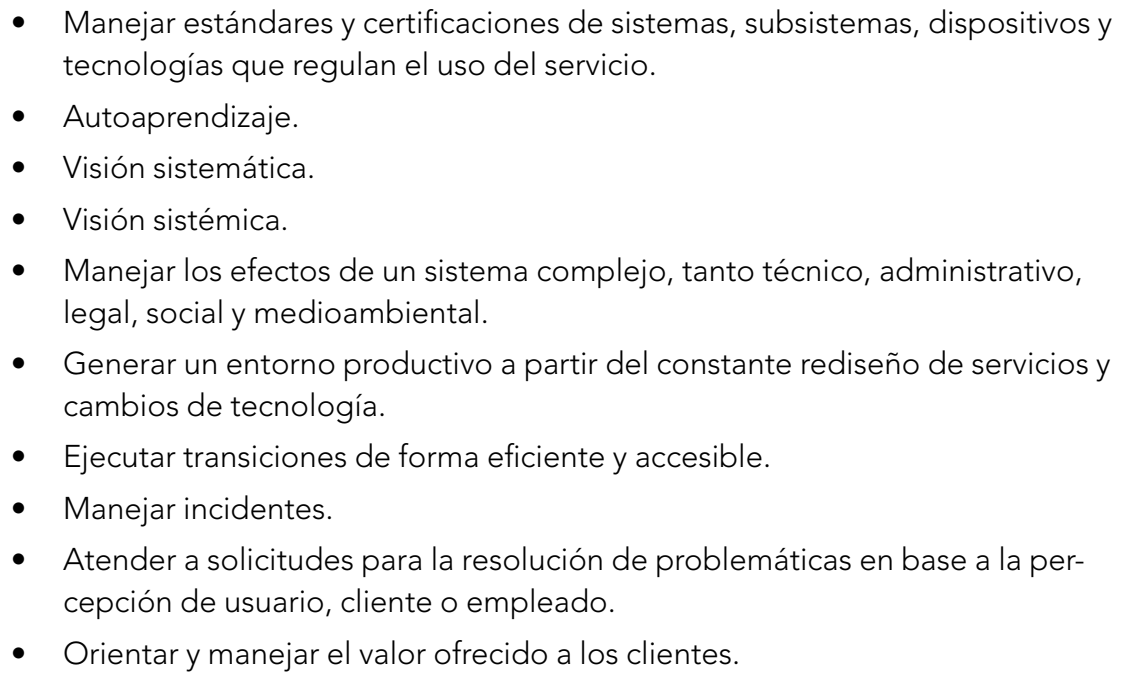 & $\begin{array}{l}\text { Visionaria } \\
\text { Responsable } \\
\text { Ética }\end{array}$ \\
\hline
\end{tabular}

\subsubsection{Las consideraciones del Perfil de Competencia Tecnológica sobre el conocimiento del sector de ER}

En el segundo eje, sobre las consideraciones de la industria energética del Perfil de Competencia Tecnológica, se realiza una caracterización del sector de ER en Baja California, en el marco de las políticas públicas federales, el análisis de la reforma energética y el programa especial para el aprovechamiento de ER, así como de documentos que explican la transición y el desarrollo de ER. Además, se estudió la estructura industrial en el Estado, los proyectos que actualmente se encuentran en desarrollo y el crecimiento histórico 
del sector a partir del impulso empresarial. La revisión conjunta de referencias teóricas e informes técnicos y algunas categorías de la evaluación cualitativa formalizan los elementos claves para determinar las consideraciones de la industria necesarias dentro de un Perfil de Competencia Tecnológica de los líderes en el sector de ER. Dichos elementos se desglosan a manera de habilidades, capacidades o acciones que un líder de empresa deberá cubrir en un marco de innovación y desarrollo tecnológico (tabla 5).

Tabla 5. Consideraciones del conocimiento de las ER del Perfil de Competencia Tecnológica Análisis de organizaciones gubernamentales y disposiciones que se relacionen a la temática en un marco internacional, nacional y regional. Estudio de instituciones de educación superior y centros de investigación regionales, asesoría de un grupo preseleccionado de expertos.

\begin{tabular}{|c|c|c|}
\hline Conocimiento & Habilidad & Actitud \\
\hline $\begin{array}{l}\text { Calidad de } \\
\text { servicio }\end{array}$ & $\begin{array}{l}\text { - } \text { - } \text { Reducir los costos de productos y servicios sin afectar la calidad. } \\
\text { - } \text { Incrementar la calidad de productos y servicios. } \\
\text { - } \quad \text { Participar en capacitación y certificación en organismos gubernamentales. } \\
\text { - } \quad \text { Promover los esquemas de regulación y reglamentación del mercado de ER. } \\
\text { - } \quad \text { Promover y gestionar modelos de evaluación y certificación en temáticas } \\
\text { - } \quad \text { técnicas sobre ER. } \\
\text { - } \quad \text { sistemas para la generación de ER. } \\
\text { - } \text { Modernizar la planta productiva para la generación de ER. } \\
\text { - Relacionar los recursos naturales en el Estado con el desarrollo de pro- } \\
\text { yectos de ER. }\end{array}$ & $\begin{array}{l}\text { Compromiso } \\
\text { Ética } \\
\text { Planificadora } \\
\text { Visionaria }\end{array}$ \\
\hline
\end{tabular}




\begin{tabular}{|c|c|c|}
\hline Conocimiento & Habilidad & Actitud \\
\hline $\begin{array}{l}\text { Industria y } \\
\text { Gobierno }\end{array}$ & $\begin{array}{l}\text { - Comprender y aprovechar las políticas públicas que apoyan la genera- } \\
\text { - } \text { Adón de ER. } \\
\text { - Cooperar con el sector público para identificar nichos de mercado de } \\
\text { biocombustibles y mezclas. } \\
\text { - Establecer relación y colaboración con instituciones gubernamentales } \\
\text { que apoyan la generación de ER. } \\
\text { - Analizar y comprender el desarrollo de la industria de ER a partir de la } \\
\text { planeación estratégica nacional, revisando a detalle el Plan de Desarrollo } \\
\text { - Idecional, el Plan de Desarrollo Estatal y la Reforma Energética, entre otros. } \\
\text { creadas para el desarrollo de proyectos energéticos en México (Comité de } \\
\text { Gestión por Competencias de Energías Renovables y Eficiencia Energética, } \\
\text { Programa Especial de Aprovechamiento de Energías Renovables, } \\
\text { Ventanilla Nacional Única, Comisión Reguladora de Energía, entre otras). } \\
\text { - Informarse de forma permanente sobre los programas estatales de apo- } \\
\text { - yo a la generación de ER. } \\
\text { Fomentar y participar en los estándares de competencias sobre eficien- } \\
\text { cia energética y ER del Conocer. } \\
\text { Participar en las reuniones y mantener una comunicación activa con el } \\
\text { subcomité especial de energía en el Estado. } \\
\text { aislamiento de la red eléctrica nacional. }\end{array}$ & $\begin{array}{l}\text { Cooperativa } \\
\text { Participativa } \\
\text { Liderazgo } \\
\text { Comunicativa }\end{array}$ \\
\hline Industria e I+D & $\begin{array}{l}\text { - Integrar o participar en grupos de colaboración en donde se involucre } \\
\text { - } \text { Pobierno-industria-institución de educación superior. } \\
\text { y cuidado del medio ambiente. } \\
\text { - Fomentar la cultura sostenible en la industria y la sociedad. } \\
\text { - Identificar profesiones de innovación e incorporar profesionales en pro- } \\
\text { - } \text { Pesos para la generación de ER. } \\
\text { ción puntual de necesidades y el análisis de factibilidad de electrificación } \\
\text { por medio de ER. } \\
\text { - Vincularse con los centros mexicanos de innovación en energías, según } \\
\text { - Participar en foros y conferencias académicas para la promoción de } \\
\text { servicios o presentación de proyectos aplicativos. } \\
\text { Estructurar y promover programas de estancia a estudiantes con la inten- } \\
\text { ción de que se integren a proyectos de la empresa. } \\
\text { - Apoyar la estructura de un departamento de innovación y desarrollo } \\
\text { para la creación de nuevos productos y servicios. } \\
\text { Sensibilizar a las empresas de diversos sectores sobre la necesidad de } \\
\text { crear un área o departamento para la gestión energética con la intención } \\
\text { de desarrollar proyectos en base a ER que les permitan el aprovecha- } \\
\text { miento y ahorro de recursos. }\end{array}$ & $\begin{array}{l}\text { Cooperativa } \\
\text { Integradora } \\
\text { Participativa } \\
\text { Responsable } \\
\text { Reflexiva }\end{array}$ \\
\hline
\end{tabular}




\begin{tabular}{|c|c|c|}
\hline Conocimiento & Habilidad & Actitud \\
\hline $\begin{array}{l}\text { Industria de } \\
\text { exportación }\end{array}$ & $\begin{array}{l}\text { - Valorar la incorporación de estándares internacionales sobre eficiencia } \\
\text { - } \text { Anergética. } \\
\text { - } \text { Difundizar los cambios climáticos y la necesidad de reducir contaminantes. } \\
\text { sidad de reducir contaminantes. } \\
\text { - Conectar con la industria de ER a nivel internacional para la adquisición } \\
\text { - } \text { - Vinculación con la industria internacional para el impulso de su empresa. } \\
\text { - Buscar la inversión extranjera para el desarrollo de bioenergéticos. } \\
\text { - Desarrollar estrategias para la planeación y exportación de productos o } \\
\text { - } \text { Eservicios para la generación de ER. } \\
\text { - Alemania (Giz) con sede en México. } \\
\text { Establecer alianza con la Comisión de Cooperación Ecológica Fronteriza } \\
\text { (cocef). }\end{array}$ & $\begin{array}{l}\text { Confianza } \\
\text { Cordial } \\
\text { Liderazgo } \\
\text { Promotor } \\
\text { Respeto } \\
\text { Tolerancia }\end{array}$ \\
\hline
\end{tabular}

\subsubsection{Las consideraciones del Perfil de Competencia Tecnológica sobre el conocimiento de la innovación empresarial}

El tercer eje, que indica las consideraciones de innovación empresarial, está compuesto por los indicadores que representan condiciones estrictamente ligadas a un enfoque de estudios de mercado, crecimiento empresarial, desarrollo económico, innovación dentro de las empresas; es imposible desprenderlo del marco administrativo y económico, puesto que representa el núcleo de las organizaciones. Si bien, el estudio se visualiza desde la incorporación y apropiación tecnológica; al ser la empresa el elemento de estudio principal, en el cuadro selectivo de disciplinas que infieren en la estructura evaluable, se determina que el tema de innovación empresarial y los subtemas derivados como planeación estratégica, escalamiento industrial, competitividad, desarrollo de las organizaciones, liderazgo y las acciones para el crecimiento industrial son relevantes en el Perfil de Competencia Tecnológica. El listado de características claves desde la perspectiva de las empresas se visualizan en la tabla 6 , en dónde se define el conocimiento, las habilidades y las actitudes del Perfil de Competencia Tecnológica desde la temática de innovación en el sector empresarial dirigido específicamente al estudio de las PyмE en вс. 
Tabla 6. Consideraciones sobre el conocimiento de la innovación empresarial del Perfil de Competencia Tecnológica

Análisis teórico sobre tendencias administrativas de innovación; impulso y tendencias para el desarrollo de PYME

\begin{tabular}{|c|c|c|}
\hline Conocimiento & Habilidad & Actitud \\
\hline $\begin{array}{l}\text { Impulso al capital } \\
\text { humano }\end{array}$ & $\begin{array}{l}\text { - Incentivar el desarrollo e inserción laboral del capital humano } \\
\text { relacionado con las tıcc. } \\
\text { - } \quad \text { Promover el trabajo a distancia en base a las capacidades tecnológicas } \\
\text { - } \text { Motivar y financiar la constante capacitación y actualización del capital } \\
\text { humano. } \\
\text { - Promover programas internos de capacitación y actualización para el } \\
\text { - } \quad \text { Propital humano. } \\
\text { - } \quad \text { Proc dentro de la empresa. } \\
\text { - Promover el emprendimiento como parte del crecimiento de la empresa. } \\
\text { humano de la empresa. }\end{array}$ & $\begin{array}{l}\text { Comunicativa } \\
\text { Confianza } \\
\text { Cordial } \\
\text { Liderazgo } \\
\text { Planificadora } \\
\text { Solidaria }\end{array}$ \\
\hline $\begin{array}{l}\text { Mercadotecnia } \\
\text { digital }\end{array}$ & 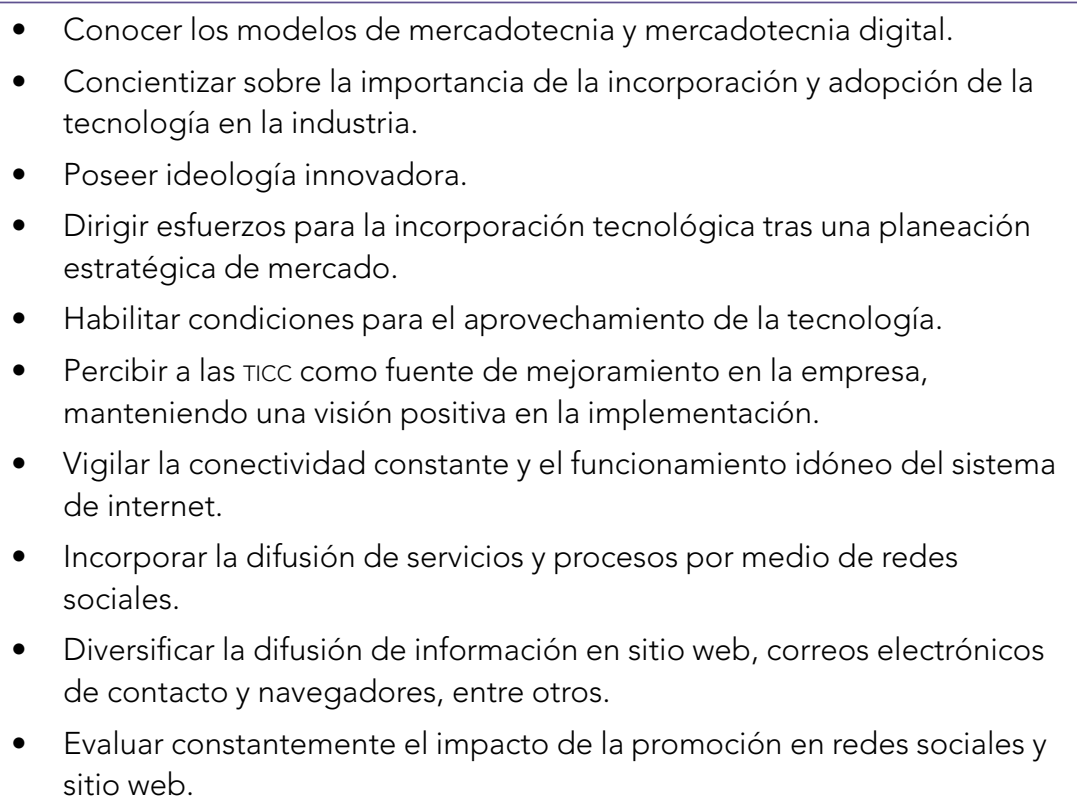 & $\begin{array}{l}\text { Participativa } \\
\text { Proactiva } \\
\text { Comunicativa }\end{array}$ \\
\hline $\begin{array}{l}\text { Colaboración y } \\
\text { cooperación }\end{array}$ & $\begin{array}{l}\text { - Participar en redes de trabajo con el sector público y privado. } \\
\text { - } \quad \text { Promover y participar activamente en el clúster de energía en el Estado. } \\
\text { - Sumarse a redes de colaboración nacional e internacional. } \\
\text { - Colaborar con diversos grupos dentro de la empresa, que permitan la } \\
\text { - } \text { transmisión y difusión del conocimiento. } \\
\text { cooperar y colaborar con otros sectores de la región involucrados en la } \\
\text { cadena de valor de ER. }\end{array}$ & $\begin{array}{l}\text { Proactiva } \\
\text { Propositiva } \\
\text { Reflexiva } \\
\text { Ética } \\
\text { Liderazgo }\end{array}$ \\
\hline
\end{tabular}




\begin{tabular}{|c|c|c|}
\hline Conocimiento & Habilidad & Actitud \\
\hline \multirow{7}{*}{$\begin{array}{l}\text { Comunicación } \\
\text { efectiva }\end{array}$} & - Integrar un plan de comunicación eficiente entre empleados y clientes. & Respeto \\
\hline & - Integrar un plan de comunicación interna, definiendo con claridad los & Tolerancia \\
\hline & medios, las frecuencias y las formas de comunicación entre el capital & Paciencia \\
\hline & humano o entre departamentos de la empresa. & Ética \\
\hline & $\begin{array}{l}\text { - Definir estrategias de comunicación efectiva con proveedores, } \\
\text { minimizando tiempos de entrega, acelerando operaciones y la } \\
\text { adquisición de insumos en menor tiempo. }\end{array}$ & Liderazgo \\
\hline & $\begin{array}{l}\text { - Integrar y socializar al interior de la empresa la cartera de clientes, } \\
\text { preferentemente con el aprovechamiento de medios digitales. }\end{array}$ & \\
\hline & - Sugerir retroalimentación a los clientes atendidos. & \\
\hline
\end{tabular}

\subsubsection{Las consideraciones del Perfil de Competencia Tecnológica sobre el contexto fronterizo}

Múltiples estudios se orientan a la revisión de las diferencias e igualdades entre las empresas que se encuentran situadas geográficamente en zona fronteriza y las que no lo están. Los resultados arrojan grandes divergencias, por tanto, sociólogos, tecnólogos y estudiosos de los mercados consideran importante situar y diferenciar la industria fronteriza como un esquema particular del gremio que no tiene la característica de ser frontera. Lo anterior, impacta en esta investigación, debido a que Baja California es uno de los Estados del norte de México que comparte frontera con E.E.u.u., específicamente con California. Por ello, en este eje se resaltan los elementos que contextualizan la entidad desde el punto de vista social, cultural, geográfico y humano en el marco de una industria que se desarrolla en frontera. Un análisis de contexto permite clarificar las condiciones en las cuales se encuentra inmerso y se desarrolla el objeto de estudio, permite tener mayores elementos para la toma de decisiones, recomendaciones y conclusiones, en su defecto. En la tabla 7 se presentan el conocimiento, las habilidades y las actitudes del líder empresarial en el contexto de la frontera norte de México. 
Tabla 7. Consideraciones sobre el conocimiento del contexto del fronterizo

Humanas, socioculturales, geográfica en el marco de la frontera norte mexicana.

\begin{tabular}{|c|c|c|}
\hline Conocimiento & Habilidad & Actitud \\
\hline Educativo & $\begin{array}{l}\text { - Dominio del idioma inglés. } \\
\text { - Difusión de mejores prácticas organizacionales. } \\
\text { - Conocer la oferta educativa en el área de ER en el Estado, desde el } \\
\text { nivel técnico a posgrado, para clarificar las potencialidades del capi- } \\
\text { tal humano en la región. }\end{array}$ & $\begin{array}{l}\text { Perseverante } \\
\text { Crítica } \\
\text { Proactiva }\end{array}$ \\
\hline $\begin{array}{l}\text { Geográfico/ } \\
\text { ambiental }\end{array}$ & $\begin{array}{l}\text { - Conocer la geografía del Estado y las potencialidades en energía } \\
\text { - Ana, eólica, geotérmica y biomasa con las que cuenta. } \\
\text { pecto al resto de México. } \\
\text { - Analizar el consumo de gas natural en el estado y la atención a la } \\
\text { demanda con ER. } \\
\text { - Conocer los indicadores alarmantes en el Estado como las condi- } \\
\text { ciones climatológicas, la disponibilidad de agua, crecimiento de la } \\
\text { población, tasa de inflación, estabilidad política y económica, desa- } \\
\text { rrollo tecnológico, competencia internacional, precio de energéticos } \\
\text { y oferta de combustibles convencionales, ente otros. } \\
\text { - Conocer y analizar la desconexión del Estado a la red eléctrica nacio- } \\
\text { nal y la baja capacidad de almacenamiento de energéticos para dar } \\
\text { respuesta con soluciones renovables. } \\
\text { Analizar la concentración de contaminantes atmosféricos en zonas } \\
\text { urbanas. }\end{array}$ & $\begin{array}{l}\text { Reflexiva } \\
\text { Proactiva } \\
\text { Promotora } \\
\text { Liderazgo }\end{array}$ \\
\hline Social & $\begin{array}{l}\text { - Atender necesidades de comunidades vulnerables que se encuen- } \\
\text { tran sin energía eléctrica por el aislamiento de la zona urbana. } \\
\text { - Identificar el índice de desarrollo humano, condiciones de vida, } \\
\text { - } \quad \text { Identificar los grupos migrantes, indígenas y discapacitados, y pro- } \\
\text { poner opciones basadas en ER para apoyar el desarrollo. } \\
\text { - Identificar la población demográfica, para establecer proyectos en } \\
\text { zonas estratégicas. }\end{array}$ & $\begin{array}{l}\text { Proactiva } \\
\text { Participativa } \\
\text { Reflexiva } \\
\text { Propositiva } \\
\text { Ética } \\
\text { Empatía }\end{array}$ \\
\hline Económico & $\begin{array}{l}\text { - Conocer las actividades económicamente activas en el Estado, prin- } \\
\text { cipalmente en dónde se requiera inversión en ER, como la actividad } \\
\text { agrícola y ganadera en los valles del Estado. } \\
\text { - Conocer y analizar las zonas de desarrollo del sector vinícola en el } \\
\text { Estado como potenciales clientes. }\end{array}$ & $\begin{array}{l}\text { Propositivo } \\
\text { Liderazgo } \\
\text { Planificadora } \\
\text { Ética } \\
\text { Empatía }\end{array}$ \\
\hline
\end{tabular}




\section{Conclusiones}

Realizar un análisis en el sector industrial implica que se considerarán además de los indicadores y requerimientos de la propia metodología de investigación, algunos otros procedimientos apegados a las áreas administrativas, económicas y de ingeniería en las que se definan instrucciones para la intervención, atención y seguimiento de proyectos en las organizaciones. Es importante asegurar el cumplimiento de las normas de calidad en la industria, así como el análisis y clasificación de empresas participantes en el estudio, con la intención de documentar datos de contexto de la muestra evaluada.

El marco de referencia teórico del Perfil de Competencia Tecnológica estudiado se estructura de la siguiente manera: a nivel internacional se consideran los lineamientos del marco europeo de las e-competencias, la ITIL y las publicaciones de investigación en el área; a nivel nacional se analizan los informes y planes de desarrollo de organismos gubernamentales del sector, considerando la Secretaría de Energía y las organizaciones que se desglosan de dicha administración, que atienden la temática de en en el país y Baja California; a nivel regional se analizaron casos de estudio, publicaciones de investigación en el sector productivo y principalmente se realiza el estudio de contexto, que se refiere a una evaluación cualitativa con expertos en el área, para determinar las necesidades en términos de tecnología y contexto. Así mismo, se integra un estudio de contexto cualitativo con investigadores expertos.

Como aportación relevante en esta investigación se describe el Perfil de Competencia Tecnológica, que se divide en cuatro ejes: el conocimiento tecnológico, el conocimiento del sector de ER, el conocimiento de la innovación empresarial y el conocimiento del contexto fronterizo, de los que derivan un conjunto de 16 conocimientos generales, 110 habilidades y 25 actitudes. La estructura del Perfil de Competencia Tecnológica posibilita la construcción de una metodología de evaluación sobre el nivel de competencias tecnológicas de los líderes del sector productivo, traduciendo las competencias mencionadas en indicadores de medición, con la intención de aportar soluciones a la problemática de la brecha digital industrial, apoyando con TICC los procesos al interior y exterior de una empresa, que funcionen como habilitadores del crecimiento económico, del nivel de competitividad de las organizaciones y que promueva el escalamiento industrial. 


\section{Referencias}

Accenture Technology Vision. (2015). Digital business era: Stretch your boundaries. Recuperado de https://www.accenture.com/_acnmedia/Accenture/Conversion-Assets/Microsites/ Documents11/Accenture-Technology-Vision-2015.pdf

Ahumada, E., Zárate R., Plascencia, I., \& Perusquia, J. M. (2012). Modelo de competitividad basado en el conocimiento: El caso de las PYME del sector de tecnologías de la información en Baja California. Revista Internacional Administración E Finanzas, 5(4).

Agencia Mexicana de Cooperación Internacional para el Desarrollo - AMEXCID-. (2012). Inauguran oficinas en México Agencia de Cooperación Internacional y Banco de Desarrollo de Alemania. Recuperado de https://www.gob.mx/amexcid/prensa/inauguran-oficinas-en-mexico-agencia-de-cooperacion-internacional-y-banco-de-desarrollo-de-alemania

Alianza Mundial de Servicios de Tecnologías de la Información —AMITI-. (2011). AмIтI. Mejores empresas de ті para México. Recuperado de http://amiti.org.mx/

Andréu, A. J. (s.f.). Las técnicas de análisis de contenido: Una revisión actualizada. Recuperado de https://perio.unlp.edu.ar/tesis/sites/perio.unlp.edu.ar.tesis/files/S200103-Las\%20técnicas\%20de\%20Análisis\%20de\%20Contenido\%20-\%20Una\%20revisión\%20actualizada.pdf

Brito, J., \& Carrillo, J. (2017). Aprendizaje sobre los límites al escalamiento: el clúster de la industria de televisores en México. Región y Sociedad, 29(70), 181-202. https://doi. org/10.22198/rys.2017.70.a320

Brito, J., Garambullo, A., \& Ferreiro, V. (2014). Aprendizaje y acumulación de capacidades tecnológicas en la industria electrónica en Tijuana. Revista Global de Negocios, 2(2), 57.

Buenrostro, M. E. (2013). Experiencias y desafios en la apropiación de las TIC por las PYMES mexicanas - Colección de Memorias de Seminarios. México: INFOTEC.

Burillo, V., Dueñas, J., \& Cuadrado, F. (2012). Competencias profesionales EтIC en mercados emergentes. Fundación Tecnologías de la Información. Madrid: FTI-AMETIC.

Cabello, R. (2004). Aproximación al estudio de competencias tecnológicas. Ponencia presentada en las IV Jornadas Nacionales de Investigadores en Comunicación, San Salvador de Jujuy.

Candolfi, N., \& Chan, M. E. (2017). Construcción conceptual de las competencias tecnológicas a partir de un análisis cronológico de su significado y su aplicación. De lo educativo a lo empresarial. En R. G. Cruz Flores \& G. A. López Morteo, Tecnologías emergentes en la educación: El ámbito educativo en la era digital (pp. 27-55). México: Pearson. 
Candolfi, N., Chan, M., \& Rodríguez, B. (2019). Technological competences: A systematic review of the literature in 22 years of study. International Journal of Emerging Technologies in Learning (IJET), 14(04), 4-30. https://doi.org/10.3991/ijet.v14i04.9118

Carrillo, J., \& Micheli, J. (2017). Huawei y Foxconn: casos pioneros de la nueva internacionalización china y su impacto regional en México. Estudios Sociales, 27(50). https://doi. org/10.24836/es.v27i50.409

Carrillo, J., Hualde, A., \& Flacso-México. (2013). ¿Una maquila diferente? Competencias laborales profesionales en la industria aeroespacial en Baja California. En M. Casalet (Ed.), $L a$ industria aeroespacial: complejidad productiva e institucional (pp. 163-198). México: Flacso México.

Carrillo, J., \& Gomis, R. (2003). Los retos de las maquilladoras ante la pérdida de competitividad. Comercio Exterior, 53(4), 318-327.

Carrillo, J., \& Hualde, A. (2000). El desarrollo regional y la maquiladora fronteriza: Las peculiaridades de un clúster electrónico en Tijuana. Mercado de Valores, 10, 45-56.

Carrillo, V. J., Villavicencio, L. D., De los Santos, S., \& Plascencia, I. (2016). Made in México: Desafíos para la ciencia e innovación en la frontera norte. México: Colegio de la Frontera Norte - COLEF-.

Carrión Latorre, V., \& Hualde Alfaro, A. (2013). ¿Profesionales sin fronteras? Una aproximación a las trayectorias laborales de los ingenieros mexicanos en Estados Unidos. RELET - Revista Latinoamericana de Estudios del Trabajo, 18(30), 71-102.

CEMIE. (2015). Centros mexicanos de innovación en energía. Recuperado de https://www. gob.mx/sener/articulos/centros-mexicanos-de-innovacion-en-energia

CFE. (2008). Ley para el aprovechamiento de energías renovables y el financiamiento de la transición energética. Publicada en el Diario Oficial de la Federación el 28 de noviembre de 2008.

CFE. (2012a). Energías renovables en CFE. Recuperado de http://www.cfe.gob.mx/ConoceCFE/ Desarrollo_Sustentable/energiarenovable/Paginas/EnergiarenovableenCFE.aspx

CFE. (2012b). Energías renovables. Recuperado de http://www.cfe.gob.mx/conocecfe/desarrollo_sustentable/paginas/energia-renovable.aspx

CFE. (2017). Comisión Federal de Electricidad. Recuperado de http://www.cfe.gob.mx/

CGCEREE. (2016). Comité de Gestión por Competencias de Energía Renovable y Eficiencia Energética. Recuperado de https://www.gob.mx/sener/documentos/comite-de-gestion-por-competencias-de-energia-renovable-y-eficiencia-energetica-35733 
Chan, M. E. (2016). Virtualization of higher education in Latin America: Between trends and paradigms. Red Revista de Educación a Distancia, (48). Recuperado de https://revistas. um.es/red/article/view/253141/0

Chomsky, N. (1965). Aspects of the Theory of Syntax. Cambridge: MIT Press.

COCEF (1993). Comisión de cooperación ecológica fronteriza. Recuperado de http://www. cocef.org/

COCEF/BECC. (2013). Propuesta de certificación y financiamiento. Proyecto de Energía Eólica Sierra de Juárez Tecate Baja California y Condado de San Diego, California, usa. Recuperado de http://server.cocef.org/publicFiles/projects/ESP/DRAFT\%20BD\%202013XX\%20Energia\%20Sierra\%20Juarez\%20(ESP)\%20101013-Final.pdf

CONUEE. (2008). Comisión Nacional para el Uso Eficiente de la Energía. Recuperado de https:// www.gob.mx/conuee

Comisión Europea. (2015). Estrategia Europa 2020.Gobernanza económica de la UE. Recuperado de https://ec.europa.eu/info/business-economy-euro/economic-and-fiscal-policy-coordination/eu-economic-governance-monitoring-prevention-correction/european-semester/ framework/europe-2020-strategy_es

Contreras, O., Plascencia, I., \& Carrillo, J. (2016). Redes de producción global y aprendizaje local para la competitividad en el sector automotriz: los casos de Ford-Hermosillo y ToyotaTijuana. Mercados y Negocios, 16(8), 5-28. Recuperado de http://www.revistascientificas. udg.mx/index.php/MYN/article/view/5287

CRE. (1993). Comisión Reguladora de Energía. Secretaría de Energía. Recuperado de https:// www.gob.mx/cre

e-Competence. (2016). European e-Competence Framework. Recuperador de www.ecompetence.eu

Fuentes, N. (2008). Elementos de la política de desarrollo empresarial: El caso de Baja California, México. Reglas, Industria y Competitividad, 152-172.

Fuentes, E. C. (2011). Proyecto de Interconexión del Sistema Baja California con el Sistema Interconectado Nacional. México: CFE.

García Alcaraz, J. L., \& Romero González, J. (2011). Valoración subjetiva de los atributos que los ingenieros consideran requerir para ocupar puestos administrativos: Un estudio en empresas maquiladoras de Ciudad Juárez. Revista mexicana de investigación educativa, 16(48), 195-219.

García, M. V., Martín, T. I., \& Casado, M. A. (2009). Capital humano: el gestor del conocimiento, el trabajador intelectual y el sistema de remuneración basado en el conocimiento. Trabajo 11, 35-52. 
Gasca, L. K. (2015). Reforma energética en México. México: SENER.

Gil Gómez H. (2003). Aprendizaje interorganizativo en el entorno de un Centro de Investigación Tecnológico. Aplicación al sector textil de la Comunidad Valenciana (tesis doctoral, Universidad Politécnica de Valencia, España).

GIZ. (2012). Estudio para determinar cualitativamente y cuantitativamente la demanda de personal calificado en energías renovables en México. GIZ, Ministerio Federal de Cooperación Económico y Desarrollo, Cooperación Estados Unidos Mexicanos - República Federal Alemana. México: @Deutsche Gesellschaft für Internationale Zusammenarbeit (GIZ) GmbH.

GIZ. (2017). Deutsche Gesellschaft für Internationale Zusammenarbeit. Recuperado de https:// www.giz.de/en/worldwide/33041.html

GOB-BC (2015). Programa Especial de Energía 2015-2019. Mexicali: Gobierno del Estado de Baja California.

GOB-PEAER. (2013). Programa Especial para el aprovechamiento de energías renovables. Plan Nacional de Desarrollo 2013-2018. México: Secretaría de Energía.

González, J. A. (1999). Tecnología y percepción social evaluar la competencia tecnológica. Estudios sobre las Culturas Contemporáneas, 5(9), 155-165.

Gomis, R., \& Carrillo, J. (2016). The role of multinational enterprises in the aerospace industry clusters in Mexico: The case of Baja California. Competition $\&$ Change, 20(5), 337-352. https://doi.org/10.1177/1024529416656511

Hernández, J., \& Carrillo, J. (2018). Possibilities of Mexican smes insertion in the aerospace industry value chain, the Baja California. Estudios Fronterizos, 19, e002. https://doi. org/10.21670/ref.1802002

Hymes, D. (1974). Pidginization and creolization of languages. Proceedings of a conference beld at the University of the West Indies Mona, Jamaica, April 1968. Cambridge University Press.

Hualde, A. (2001). Del territorio a la empresa: conocimientos productivos entre los ingenieros del norte de México. Región y Sociedad, 13(21), 3-45.

Hualde, A., \& Díaz, P. C. (2010). La industria de software en Baja California y Jalisco: dos experiencias contrastantes. Estrategias empresariales en la economía basada en el conocimiento. México: CONCYTEG, SINNCO.

Hualde, A., Carrillo, J., \& Domínguez, R. (2008). Diagnóstico de la industria Aeroespacial en Baja California. Características productivas y requerimientos actuales y potenciales de capital humano. Proyecto Fondo Mixto de Baja California. Tijuana: Colegio de la Frontera Norte. 
IFT. (2018). Adopción de las TIC y uso de internet en México. México: Instituto Federal de Telecomunicaciones.

IMCO. (2006). Visión México 2020. Políticas Públicas en materia de Tecnologías de la Información y Comunicaciones para impulsar la Competitividad de México. México: Concepto Total s.A. de c.v.

ITIL. (2017). Training Academy. The Knowledge Academy. Recuperado de https://www.itil. org.uk/

INEEL. (2001). Instituto Nacional de Electricidad y Energías Limpias. Recuperado de https:// www.gob.mx/ineel/

Lansati, M. (2005). Why Iт matters in midsize firms. Keystone, HBD Working Paper. Recuperado de https://hbswk.hbs.edu/item/why-it-matters-in-midsized-firms

Lévesque, C., Bensusán, G., Murray, G., Novick, M., Carrillo, J., \& Gurrera, M. S. (2015). Labour relations policies in multinational companies: A three-country study of power dynamics. The Journal of Industrial Relations, 57(2), 187-209. https://doi.org/10.1177/0022185614564377

Marzo, N. M., Pedreja, I. M., \& Rivera, T. P. (2006). Las competencias profesionales demandadas por las empresas: el caso de los ingenieros. Revista de Educación, (341), 643-662.

Motta, J. J., Zavaleta, L., Llinás, I., \& Luque, L. (2013). Innovation processes and competences of human resources in the software industry of Argentina. Revista CTS, 8(24), 147-175.

Matus, M., Carrillo, J., \& Gomis, R. (2018). Empresas multinacionales, derramas de conocimiento y spin-off en México. ¿El país de origen hace la diferencia? Perfiles latinoamericanos, 26(52). https://doi.org/10.18504/p12652-007-2018

Moraleda, A. (2004). La innovación, clave para la competitividad empresarial. Universia Business Review, 1, 128-136.

Muñoz, A. (2016). Transformación digital: solo 1 de cada 3 empresas está preparada. Recuperado de http://www.ticbeat.com/empresa-b2b/transformacion-digital-solo-1-de-cada-3-empresas-esta-preparada/

Núñez-Torrón, S. A. (2016). Las 7 competencias imprescindibles para la transformación digital. Recuperado de http://www.ticbeat.com/innovacion/competencias-imprescindibles-transformacion-digital/

OCDE. (2017). Digital Economy Outlook 2017. Recuperado de https://www.oecd-ilibrary.org/ sites/9789264276284-en/index.html?itemId=/content/publication/9789264276284-en\&_csp_=e4436 ff8f3d3422fd04e442d89d813fb\&itemIGO=oecd\&itemContentType=book

Ordoñez, J. E., Gil-Gómez, H., Oltra, B. R., \& González-Usach, R. (2015). Importancia de las competencias en tecnologías de la información (e-skills) en sectores productivos. $3 C$ TIC, 
4(1), 87-99. https://www.3ciencias.com/wp-content/uploads/2015/03/IMPORTANCIADE-LAS-COMPETENCIAS-EN-TECNOLOGÍAS-DE-LA-INFORMACIÓN.pdf

Patel, P., \& Pavitt, K. (1997). The technological competencies of the world's largest firms: complex and path-dependent, but not much variety. Research Policy, 26(2), 141-156.

Pérez-Jácome, D., \& Aspe, M. (2012). Agenda Digital.mx (Vol. 1). México: Secretaría de Comunicaciones y Transportes.

PND. (2013). Plan Nacional de Desarrollo 2013-2018. México: Gobierno de la República.

Porter, M. (2005). ¿Que es la competitividad? Recuperado de http://www.iese.edu/es/ad/anselmorubiralta/apuntes/competitividad_es.html

Porter, M. (2009). Estrategia competitiva: Técnicas para el análisis de la empresa y sus competidores. Ediciones Pirámide.

PRODESEN. (2017). Programa de Desarrollo del Sistema Eléctrico Nacional. Secretaría de Energía. Recuperado de https://www.gob.mx/sener/acciones-y-programas/programa-de-desarrollo-del-sistema-electrico-nacional-33462

Renaud, A. (1990) Comprender la imagen hoy. Nuevas imágenes, nuevo régimen de lo visible. Nuevo imaginario. En A.A.V.V., Video culturas de Fin de Siglo (pp. 11-26). Madrid: Cátedra.

Reynaga, O., \& Ruiz, E. (2003). La investigación educativa en México 1992-2002. Educación, trabajo, ciencia y tecnología. México D.F.: Centro de Estudios sobre la Universidad Consejo Mexicano de Investigación Educativa.

Romijn, H., \& Albadalejo, M. (2002). Determinants of Innovation capability in small electronics and software firms in southeast England. Research Policy, 31(7), 1053-1067.

Sayago, S. (2007). La metodología de los estudios críticos del discurso. Problemas, posibilidades y desafíos. Discurso y Crítica Social, 45-60.

Sampedro, H. J. (2003). Aprendizaje y acumulación de capacidades tecnológicas en la industria maquiladora de exportación: el caso de Thomson-Multimedia de México (tesis doctoral, Universidad Autónoma Metropolitana, México).

Secretaría de Economía de México. (2014). Dirección General de Programas para MIPYME. Recuperado de https://www.inadem.gob.mx/direccion_general_de_programas_para_miPyME.html

Select. (2005). Select en tus decisiones TIC. Recuperado de www.select.com.mx

SENER. (2010). Prospectiva de Talento del Sector Energía - Volumen 5 Recursos Humanos escenarios 2, 5 y 10 años para el subsector de Sustentabilidad Energética. México: Secretaría de Energía. 
SENER. (2011). Prospectiva de Energías Renovables 2012-2026. Gobierno Federal. México: Secretaría de Energía.

SENER. (2013). Secretaría de Energía. Gobierno Federal. Recuperado de https://www.gob. $\mathrm{mx} /$ sener

SENER. (2016a). Comisiones Estatales de Energía. Secretaría de Energía. Recuperado de http:// www.conuee.gob.mx/wb/Conuee/comisiones_estatales_de_energia.

SENER. (2016b). Comité de Gestión por Competencias de Energía Renovable y Eficiencia Energética. Recuperado de https://www.gob.mx/sener/documentos/comite-de-gestion-por-competencias-de-energia-renovable-y-eficiencia-energetica-35733

SIE. (2015). Sistema de Información Energética. Recuperado de http://sie.energia.gob.mx/

Subsecretaría SENER. (2015). Prospectiva de talento del sector energía. Secretaría de Energía, Subsecretaría de Planeación y Transición Energética. México: Gobierno Federal.

Tishman, S., \& Andrade, A. (1998). Thinking dispositions: A review of current theories, practices, and issues. Harvard University, Active Learning Practices for Schools.

UNEP (2015). Climate action. Recuperado de http://www.cop21paris.org/

Urraca, R. A. (2013). Especialización tecnológica, captura y formación de competencias bajo integración de mercados; comparación entre Asia y América Latina. Economía y Sociedades, 22(3), 641-673.

Vázquez, B., Estrada, H., \& Reyes, A. (2014). Mextic en la búsqueda de nuevos horizontes. Casos de estudio 3 (pp. 19-28). Ciudad de México: Infotec Conacyt.

Villanueva, G., \& Casas, M. D. (2010). E-Competencias: nuevas habilidades del estudiante en la era de la educación, la globalidad y la generación de conocimiento. Signo y Pensamiento, 29(56), 124-138. https://doi.org/10.11144/Javeriana.syp29-56.enhe

Vílchez, G. N. (2004). Enseñanza de la Geometría con utilización de recursos multimedia. Aplicación de la primera etapa de educación básica. España: Universitat Rovira I Virgili. 